\title{
Zakharia Pourtskhvanidze
}

Johann Wolfgang Goethe University, Frankfurt

\section{DIMTEGU \\ Some Prerequisites of International Education Project}

\begin{abstract}
International educational projects play a key role in creating the rightful architecture of modern society. A central point in this process is the enquiry to identify and elicite most urgent problems in national educational systems in the world. The concerned part of society builds up shortcomings of the actual system through educational structures. Therefore, while identifying the problem it is necessary to analyse the influences of the system on the target groups. The gap in an educational system cannot be invented; it can be solely recognized through the contact with the impacted part of society.

The central concern of an educational project must be the identification and solution of the problems. The problems can be caused by certain social, political and ethnological situations in certain societies.
\end{abstract}

\section{Multilingualism as way of life}

Education in most countries of the world takes place in plurilingual environment. It does not mean necessarily, that the governments in such of countries recognise the multilingualism as the relevant field of work. The reason of the political ignorance of multilingualism is often the hierarchy within the languages regarding their status. A multilingualism contains the social relations triggered by be or trilingual peoples. As a rule, they master the mother tongue as well as the official language of state. Additionally, they 
articulate one language of adjoining countries. The status of those languages are not same and are defined by different social needs. The use of the mother tongue is limited by home relationships, whereas the language of constitution is necessary for official practices and it is the language of instruction, hence very important for the education. Many societies treat the home language as privet problem and often suppress it from actual social agenda.

The firs crucial prerequisite of the initiation of international multilingual educational projects is the generating of the strong awareness regarding multilingualism and the relevancy of the multilingual education.

The successful stories and productive practices in context of multilingualism should be promoted. There is a lot of persuading to do in the ground phase project initiation. The main goal of work should be the establishment of the perspective, that the multilingualism is more a way of life than a problem to be solved.

The linguistic diversity represents a trigger of cultural pluralism. In the $21^{\text {th }}$ century the multicultural co-work generates the social wealth and prosperity. The social and political agreement regarding that point in many countries makes the initiation and implementation of international education projects simpler and more effective.

\section{The plan of the adaptation.}

The challenge is for education systems to adapt to these complex realities and provide a quality education which takes into consideration learners' needs, whilst balancing these at the same time with social, cultural and political demands.

It is utopian to think, that it would be possible to design a kind of the uniform project frame for all plurilingual societies and provide the universal plan for the solution of 
administrative and managerial problems. There is no standard model, which can be used in universal way and represents a general problem solver.

Hence, the second important prerequisite of successful educational project represents the junction of the multilingual social reality to existing educational structures.

As a rule, the state governed educational system is aligned to the dominant language of the country and tolerates not always the minor languages. In such cases we speak about disaccord between the real social condition and the policy. The 'Adaptation' is the key word: the education project has to design the unique work plan, which considers certain conditions of the certain society. It means the pre-field research about deficits of given education system regarding the realities of multilingual life. The affected officials and lows should be defined as parts of the adaptation plan. By the using of survey, the target groups of the project should be localized and descripted. In first the phase of project plan preparation it is a lot of persuading to do namely with representatives of the official education systems as well as with identified target group. The term 'adaptation' takes here again an important place.

\section{Language(s) of instruction.}

The starting point of multilingual education project initiation is to create the language hierarchy with official language of instruction as central point. All other languages occur the different positions around the official language and represent different relations to it. That ideal picture of language hierarchy does not work in most of cases:

there are more than 20 States with more than one official language (India has 19 official languages while South Africa has 11), the majority of countries in the world are monolingual nation states in the sense of 
recognizing, de jure or de facto, only one official language for government and legal purposes. That is not to say that they are not bilingual or multilingual societies, but rather that while there may be many languages widely used in a country these do not necessarily have the legal authority of an official language.

How does this happen?

In many countries that were previously under colonial regimes, the official language tends to be the language of the former colonizers. In addition to official languages, several countries recognize national languages, which may be compulsory in education. The choice of language in the educational system confers a power and prestige through its use in formal instruction. Not only is there a symbolic aspect, referring to status and visibility, but also a conceptual aspect referring to shared values and worldview expressed through and in that language.

The third prerequisite of education project initiation is the accurate study of near social history and the political development of the project target society. Many official languages do not mean automatically, that all of them are on the same stage of status. Some languages bear more prestige and promise to provide more benefit in the future. Some other official languages bear more symbolic character and represent the genuine part of legendary past. The study of differentiations between official languages should be design a specific model, which has to help to direct the necessary attention within the multilingual education project to corresponding languages. The mother tongue should be the object of peculiar attention.

Studies have shown that, in many cases, instruction in the mother tongue is beneficial to language competencies in the 
first language, achievement in other subject areas, and second language learning. The application of the principle of mother tongue instruction nevertheless is far from being the rule.

The using of the mother tongue as primary language of instruction is not always unproblematic. Some of the difficulties encountered by the use of mother tongues as languages of instruction may include the following:

- sometimes the mother tongue may be an unwritten language;

- sometimes the language may not even be generally recognized as constituting a legitimate language;

- the appropriate terminology for education purposes may still have to be developed;

- there may be a shortage of educational materials in the language;

- there may be a lack of appropriately trained teachers;
- there may be resistance to schooling in the mother tongue by students, parents and teachers.

\section{Closing remarks.}

During the preparation of the multilingual education projects some necessary prerequisites are to consider. The establishing of peculiar awareness to multilingualism as the way of life; The recovering of deficits and needs of the certain education system regarding multilingualism and adaptation of given social reality in it; The creation of certain educational model, which is fitted within the language relations of the given society and helps to improve the social life. 